\title{
Thoughts on Drug Policy, Public Health, and Crime: More Support for Decriminalization
}

\author{
DOUGLAS HUSAK ${ }^{\star}$
}

\section{Who I Am and What I Do}

The various thoughts I express in this paper are divided into five parts. I begin with a few brief comments about myself. I am a legal philosopher --- one of the few with a strong interest in drug policy. Not many philosophers are as interested in drug policy as I am, and none of them has been interested in it for as long as I. Surely the reason so few philosophers specialize in this topic is because the issues are so empirical, and many philosophers are notoriously allergic to facts. To have a deep interest in drug policy requires a willingness to wrestle with facts from many different disciplines --- sociology, political science, pharmacology, psychology, history, biology, economics, neuroscience and criminology, to name just a few. I am fascinated by what the foregoing disciplines contribute to the ongoing debate. But I have only scratched the surface. No one should profess to have a handle on all aspects of the massive puzzle that is drug policy. It is impossible to keep up. Drug policy is an enormous inter-disciplinary puzzle, and philosophy is only a tiny part of a piece. In much of this discussion I will draw from criminology in particular, because I have always believed it to be especially salient in the drug decriminalization debate. For better or worse, nearly all of my data comes from the United States---mostly from New York City, my current home---and I am unsure whether and to what extent the findings I'll discuss can be generalized to other places in the United States, much less to Norway ---where rates of drug use and violence have always been lower. But these data at least show us what is possible in the real world---a place where philosophers seldom tread.

* Distinguished Professor of Philosophy, Rutgers University.

This is an Open-access article distributed under the terms of the Creative Commons Attribution 3.0 Unported License (http://creativecommons.org/licenses/ by/3.0/), permitting all use, distribution, and reproduction in any medium, provided the original work is properly cited. 
One noteworthy aspect of the debate about drug policy is that it invariably concerns the criminalization of drugs. My focus is on this question too; I come to the topic from an interest in criminal law and criminal law theory more generally. But almost none of the literature focuses on the moral issue of whether or not persons should or should not use drugs. These two topics are similar, but different. It is certainly conceivable that the use of a given drug should be decriminalized even though that drug would be morally impermissible (and prudentially unwise) to use. Thus when I defend drug decriminalization, I should not be misunderstood to recommend or endorse drug use.

So, much of the issue is empirical. Of course, many of these empirical findings are contested. But my view about the normative philosophical framework in which these alleged facts are situated has remained relatively unchanged for thirty years. Every now and then I learn something new philosophically as opposed to empirically, and I'll mention one of these recent insights at the end of my presentation. After this little autobiography in part 1, I'll talk in part 2 about drugs as a public health problem; mention in part 3 some empirical results that are germane to whether drug proscriptions can be justified because of their causal role in contributing to crime, hazard a few observations in part 4 about how a society should deal with drug problems, and say a few words in part 5 about the recent opiate overdose epidemic plaguing much of the United States. My overall conclusion is that a good rationale for drug prohibitions has yet to be found, and the liberal alternative to criminalization, which recommends that drug use be treated as a public health problem, is problematic as well---even though it certainly would be an improvement on the status quo.

\section{Drug Criminalization and Public Health ${ }^{1}$}

Opinion surveys indicate that support for decriminalizing the use of some or all illicit drugs is at an all-time high throughout the United States. ${ }^{2}$ Outside of the special case of marijuana, however, almost no actual legal progress can be detected. The growing opposition to our existing approach appears to be based on grounds of both principle and policy. As a matter of principle, hysteria about the dangers of drugs seems to have abated. The percentage of living citizens who have used an illicit drug at some point in their lives continues to rise and now represents a clear majority in the United States. Their personal experience confirms that illicit drug use per se is not sufficiently risky to merit

1 Some of this material is drawn from Husak, Drugs, Crime, and Public Health: A Lesson from Criminology in Criminal Law, Philosophy, and Public Health Practice, eds. Coggon, Kessel and Viens (Cambridge University Press 2013) p. 42.

2 CBS News: 'Marijuana Legalization Support at All-Time High' (20 April 2017), https://www. cbsnews.com/news/support-for-marijuana-legalization-at-all-time-high/. 
the extreme punishments authorized by law. ${ }^{3}$ As a matter of policy, greater numbers of individuals regard our present approach as both ineffective and counterproductive. At home, drugs are easier to obtain now than when the war was declared. Internationally, efforts to curb supply have caused devastating consequences around the world. ${ }^{4}$ As state governments become starved for resources and painful cuts must be made, taxpayers question whether they are reaping a reasonable return for their ongoing investment in our punitive drug policy.

I deny that these punitive policies were ever defensible as a matter of justice. ${ }^{5}$ In a series of books and articles, I have argued that we should decriminalize the use of all illicit drugs. ${ }^{6}$ I reach this conclusion by applying general principles of criminalization. These principles must be satisfied if the enactment and enforcement of a penal statute is to be justified. ${ }^{7}$ In my hands, these principles take the form of constraints or necessary conditions on the content of the substantive criminal law. ${ }^{8}$ Of course, the content of these principles of criminalization is highly controversial. But commentators from all points along the political spectrum tend to agree that western countries and the United States in particular are guilty of overcriminalization---of punishing a broader range of conduct than should be allowed. We in the United States are notoriously guilty of over-punishment---of exceeding any reasonable proportionality constraints. In the case of drugs, I gather this is true in Norway as well. In the United States, Norway has a reputation for having what may be the world's most enlightened and progressive system of penal justice. Yet the regime of drug prohibitions represents a startling departure from this generalization. If we are serious about retarding the size and scope of the penal sanction, drug offenses would be a sensible place to begin almost anywhere.

Since theorists have reached no consensus about the meaning of such terms as legalization or decriminalization, ${ }^{9}$ it is easy to misunderstand how my general views about

3 Generally, see Robinson: 'Crime and Punishment in New Jersey: The Criminal Code and Public Opinion on Sentencing', http://www.drugpolicy.org/njcrime (2011).

4 See: 'War on Drugs: Report of the Global Commission on Drug Policy' (June 2011). Available at www.globalcommissionondrugs.org.

5 It may be mistaken to assume, however, that drug policy is designed to reduce drug use. For an alternative rationale, see Husak, Drug Proscriptions as Proxy Crimes, 36 Law and Philosophy 345 (2017).

$6 \quad$ See Husak, Drugs and Rights (Cambridge University Press 1992), Husak: Legalize This! (Verso 2002) and Husak and de Marneffe, The Legalization of Drugs (Cambridge University Press 2005).

7 See Husak, Overcriminalization (Oxford University Press 2008).

$8 \quad$ But see Tadros, Wrongs and Crimes (Oxford University Press 2016).

9 See Husak, Four Points About Drug Decriminalization, 22 Criminal Justice Ethics 21 (2003). In case my definition does not seem easy to misunderstand, it is noteworthy that what I call decriminalization in the context of illicit drugs is nearly identical to what is typically described as prohibition in the history of alcohol policy. 
criminal law apply to drug policy. What $I$ mean by proposals to decriminalize the use of a given drug is simple---deceptively so. I mean that the use (and possession for use) of that drug would not be a criminal offense. I take it to be a conceptual truth that offenses are criminal when they subject persons to state punishment. So anyone who thinks that the use of a given drug should be decriminalized believes that persons should not be punished merely for using it. Decriminalization is not just de-incarceration; lots of punishments---by far the majority---do not involve imprisonment. Decriminalization means the end of all punishments, including fines and sentences of probation. Admittedly, this conclusion must be established drug-by-drug, and surely is more compelling for some drugs than for others. Still, I will ignore these important differences between drugs because I believe that the case in favor of punishing users of any existing drug fails to satisfy the normative criteria in our best theory of criminalization.

So far, my thesis is wholly negative and leaves open the question: what should be done to illicit drug users? What I call the liberal position is to treat illicit drug use as a public health problem. Most Americans now embrace the liberal position. For the most part, commentators who adopt a public health approach to drug policy presuppose a framework of harm-reduction. In this part I propose to comment on the liberal position as so construed. As an academic philosopher, however, I must proceed with caution. The great bulk of the literature on drugs and harm-reduction has been produced by social scientists. These scholars are adept at empirical analysis, and we philosophers tread on their turf at our peril.

Elsewhere I have been critical of the tendency to apply a harm-reduction perspective to all questions about drug policy. ${ }^{10}$ The cost-benefit, consequentialist framework of harm-reduction is notoriously indifferent to rights and to the deontological considerations I believe to lie at the heart of many normative questions about punishment. ${ }^{11}$ In addition, cost-benefit analyses tend to do a much better job quantifying the harms than the benefits of drug use. ${ }^{12}$ Once the benefits are identified, they are difficult to weigh against harms on a common scale to yield an overall balancing. Nonetheless, I have no special quarrel with a harm-reduction model in the present context. The issues I will discuss extend beyond decriminalization as I have defined it, which pertains only to drug

10 See Husak, Competing Rationales for Drug Policy Reform in Drugs and Society, ed. Fish (Rowman \& Littlefield 2006) p. 97.

11 Drug policy is dominated by a simple-minded utilitarianism that does not approach penal justice within a deontological framework. For example, recent commentators write 'the plausibility of moving to a no-coercion drug policy depends on how much drug abuse current policies actually prevent. Caulkins, Hawken and Kleiman, Drugs and Drug Policy: What Everyone Needs to Know (Oxford University Press 2011) p. 19.

12 Kleiman and his co-authors at least raise the question of whether the pleasure caused by drug use counts as a benefit, but do not pursue the matter and stop short of trying to answer it. Id., p. 138. 
use. A comprehensive policy should endeavor to describe how drug markets should be structured to produce sensible results. As inherently public institutions, markets are more subject to evaluation by the cost-benefit, consequentialist framework which I believe is incomplete when applied to questions about use itself.

What exactly do liberals mean when they say that we should treat illicit drug use as a public health problem? They often mean (inter alia) that we should expand treatment for drug users. To many ears, pleas to expand the availability of treatment sound like an alternative to our punitive approach. But this proposal need not involve a retreat from our heavy reliance on criminal justice. Many thinkers regard the continuation of punishment for drug use as instrumental in ensuring the effectiveness of treatment and thus resist outright decriminalization. That is, they favor the retention of penal sanctions in order to increase the likelihood that persons will comply with treatment regimes, since the success of just about any type of treatment depends on the willingness of persons to cooperate with it. The proliferation of drug courts over the past two decades may seem to provide a perfect illustration of how criminal penalties can exist comfortably alongside a treatment regime. ${ }^{13}$ Although persons enter drug court through the coercive avenue of arrest, the rhetoric of these courts is solidly therapeutic rather than punitive. Thus drug courts may seem to involve a key component of a liberal, public health approach to drug use.

After an early wave of positive reviews, more recent evidence indicates that drug courts are much less effective than their advocates had hoped in providing a viable public health approach to drug use. ${ }^{14}$ Many explanations can be given for the failure of drug courts to achieve their lofty aspirations, but the root of the problem, I believe, is that these courts are rooted firmly within a framework of criminal prohibitions for drug use. ${ }^{15}$ This framework creates several tensions; two are significant for present purposes. ${ }^{16}$ Firstly, drug problems are notoriously difficult to overcome; relapse among addicts is the rule rather than the exception. But abstinence is the ideological objective to which nearly all courts aspire. As a result, it is inevitable that a great many defendants fail to complete the treatment regime mandated and overseen by the drug court judge. Incarceration is the typical response to such failures. Often these persons are incarcerated for longer terms than would have been imposed had they accepted plea bargains and declined to enter

13 The best monograph is Nolan Jr., Reinventing Justice: The American Drug Court Movement (Princeton University Press 2001).

14 See Husak, Retributivism, Proportionality, and the Challenge of the Drug Court Movement in Retributivism Has a Past. Has It a Future?, ed. Tonry (Oxford University Press 2011) p. 214.

15 See Boldt, A circumspect Look at Problem-Solving Courts in Problem-Solving Courts: Justice for the Twenty-First Century?, eds. Higgins and MacKinem (ABC-CLIO 2009).

16 For additional tensions, see Husak 2011 p. 214. 
drug court in the first place. ${ }^{17}$ Secondly, the existence of drug courts produces a 'net-widening' effect. More users are arrested and prosecuted because well-intentioned officials believe such persons will benefit from the treatment drug courts offer. ${ }^{18}$ As a result of these two factors, the total amount of traditional punishments inflicted on users has almost certainly increased since drug courts have proliferated. ${ }^{19}$ This cannot be the outcome drug court advocates intended.

Of course, individual drug users should be permitted to experiment with most any mode of treatment they hope will be beneficial. I am skeptical, however, that liberals should coerce persons into treatment when they do not seek help voluntarily. I can only sketch my reservations here. First, as I have indicated, we must justify what is done to persons who fail to complete the treatment into which they are coerced. If punishments for use cannot be justified, they cannot be justified for use after individuals do not succeed in treatment. Second, despite enormous variation among providers, it is hard to be impressed by the drug treatment industry as a whole---whether or not it is overseen by a drug court judge..$^{20}$ Treatment is usually expensive, often ineffective in the long run, and frequently unnecessary. Coercion for paternalistic purposes is hard to justify under the best of circumstances, and it is especially problematic when the benefit for the person coerced is uncertain. ${ }^{21}$ Astonishingly, addicts who undergo treatment are more likely to continue using drugs than those who do not enter treatment. ${ }^{22}$ In many respects, the drug treatment industry resembles the weight loss industry. The enormous resources expended on these treatments rarely produce lasting positive results. Despite billions of dollars expended annually, few treatment programs can boast of long-term success in getting patients to overcome their problems. As most dieters eventually regain their lost pounds,

17 O’Hear, Rethinking Drug Courts: Restorative Justice as a Response to Racial Injustice, 20 Stanford Law and Policy Review 463 (2009).

18 Hofman, The Drug Court Scandal, 78 North Carolina Law Review 1437 (2001).

19 See Drug Policy Alliance: 'Drug Courts are not the Answer: Toward a Health-Centered Approach to Drug Use', available at www.drugpolicy.org.

20 Admittedly, practical and ideological reasons often prevent health care professionals from implementing ideas that may actually work. For a nice discussion, see Alessi, Petry and Rush, Contingency Management Treatments of Drug and Alcohol Use Disorders in Addiction and Responsibility, eds. Graham and Poland (MIT Press 2011) p. 225.

21 See Husak, Penal Paternalism in Paternalism: Theory and Practice, eds. Coons and Weber (Cambridge University Press 2013) p. 39.

22 'Berkson's Bias' provides a possible explanation of why addicts in treatment are less likely to stop using drugs, but the phenomenon continues to puzzle drug treatment researchers. According to one commentator, 'the available evidence fails to support a pharmacological explanation of why addicts in treatment are less likely to quit using drugs ... The most important [difference] is that addicts in treatment are much more likely to suffer from additional psychiatric disorders than those not in treatment'. Heyman, Addiction: A Disorder of Choice (Harvard University Press 2009) p. 82 . 
relapse rates of opiate addicts, for example, are as high as $90 \%$. At the very least, any meager long-term benefits are purchased at an extraordinary cost.

A basic problem is that coerced treatment probably is incompatible with decriminalization as I construe it. Decriminalization precludes punishing drug users, and the question of whether coerced treatment is consistent with decriminalization depends on how one understands the concept of punishment. Unfortunately, this issue is also unsettled, and confusion abounds. Many states (eighteen, depending on how one counts) in the United States have allegedly decriminalized marijuana possession, even though most of these states allow users to be ticketed and fined (rather than incarcerated). ${ }^{23}$ Of course, whether such arrangements are compatible with what I mean by decriminalization depends on whether tickets and fines are modes of punishment rather than alternatives to punishment. Coerced treatment is vulnerable to the same uncertainty. I tend to think that both fines and coerced treatment are modes of punishment. Both intentionally impose stigmatizing deprivations, and thus satisfy what I regard as our best definition of punishment. ${ }^{24} \mathrm{~A}$ fine for overtime parking of a vehicle, for example, may not stigmatize and may be designed simply to raise revenue and to ensure compliance with a fair scheme to allocate a scarce resource (viz. the parking space). But no comparable story can be told about why persons who use or possess drugs should suffer a deprivation at all. Even though these modes of punishment are preferable to the more severe sanctions we now inflict on drug users, these sanctions are likely to be ruled out by decriminalization as defined here.

In drug courts, as elsewhere, punishments and therapy are nearly impossible to reconcile. I am skeptical that criminalizing use is compatible with an acceptable public health approach to illicit drugs, ${ }^{25}$ and I am unimpressed by treatment regimes generally. Hopefully treatment will improve someday. In what follows, therefore, I explore a possible basis to contest my skepticism about drug criminalization that does not assume therapy is ineffective. That is, I consider a reason that might justify punishing drug users in the pursuit of public health.

23 See, for example: http://en.wikipedia.org/wiki/Places_that_have_decriminalized_non-medical_ cannabis_in_the_United_States.

$24 \quad$ See Husak 2008 pp. 92-93.

25 The devastating health consequences of punishing illicit drug users are described in detail by Drucker, A Plague of Prisons: The Epidemiology of Mass Incarceration in America (New Press 2011). 
Douglas Husak

\section{Drugs and Crime: Findings from New York City}

With so many questions about the viability of a public health approach to a given issue, it is sensible to ask why illicit drugs are believed to present a public health problem in the first place. This inquiry is crucial if we hope to defend a public health approach to drug policy and assess its compatibility with criminalization. Obviously, this question has many different possible answers. ${ }^{26}$ I propose to focus on only one such answer, with no pretense that it is the most important. According to the possibility I will explore, the use of illicit drugs poses a public health problem because it causes violence. Since nearly all violence amounts to a crime, the hypothesis I will discuss is that the use of illicit drugs presents a public health problem because it causes violent crime. Some economic crimes should be included in this analysis. Even when they are not violent per se, the perpetration of economic crimes such as burglary increases the risk of violence and thus poses a problem for public health. Drug use, then, might jeopardize public health, albeit not necessarily the health of the drug user himself.

Social scientists have produced an enormous amount of literature investigating the alleged drug-crime connection. ${ }^{27}$ The most influential contribution to this topic was made quite some time ago by Paul Goldstein, who described three distinct mechanisms by which illicit drugs might cause crime. ${ }^{28}$ Drugs may cause psychopharmacological crime, somehow altering behavior and leading users to commit violent acts. Or drugs may cause economic crime, as users engage in shoplifting, theft, fraud, burglary, or robbery to obtain money to buy drugs. Finally, drugs may cause systemic crime, as illicit markets generate a number of violent activities. Of course, drugs may cause crime through more indirect paths not mentioned by Goldstein. For example, drugs may worsen academic performance or relax parental supervision of children, both factors that are linked to greater involvement in crime. ${ }^{29}$ In each of these categories, criminologists have debated whether drug use causes crime, whether crime causes drug use, or whether both have a common

26 For efforts to estimate the consequences of illicit drug use on public health, see Allen, Crime, Drugs and Social Theory (Ashgate 2007); Bean, Drugs and Crime, 3rd ed. (Willan Publishing 2008); Hammersley, Drugs and Crime (Polity Press 2008); and Stevens, Drugs, Crime and Public Health (Routledge-Cavendish 2011).

$27 \quad$ 'The relationship between drug use and criminal activity has been extensively studied by social scientists, indeed perhaps more so than any other topic in the field. Faupel, Horowitz and Weaver, The Sociology of American Drug Use, 2nd ed. (Oxford University Press 2010) p. 349.

28 Goldstein, The Drugs Violence Network: A Tripartite Conceptual Framework, 15 Journal of Drug Issues 493 (1985).

29 For a discussion of some of these complexities, see Natarajan (ed.), Drugs and Crime, Vol. II (Ashgate 2010). 
cause so that the relationship between the two is spurious. ${ }^{30}$ It may be presumptuous for a philosopher to attempt to add to this massive empirical literature. Despite my trepidation, I hope to identify the normative significance of some recent criminological findings.

An emphasis on the linkage between drugs and crime is eminently sensible for the normative purposes I pursue here. Punishments, as all philosophers agree, require a justification. How might we defend punishing persons for using illicit drugs? This practice cries out for a rationale. Surprisingly, a detailed and informed case in favor of criminalizing the use of illicit drugs has never been made. ${ }^{31}$ To where should readers be directed in the hope of finding such a rationale? In my judgment, the hypothesis that drugs substantially and unjustifiably increase the risk of violent crime constitutes the most promising of several possible justifications for imposing penal sanctions on drug users. Many of the alternative rationales that sometimes are heard---the supposition that drugs are unhealthy for the persons who use them, are deleterious to adolescents, or are just plain wrongful to consume---are more easily refuted. ${ }^{32}$ If drugs somehow cause an increase in the risk of violent crime, however, the case in favor of prohibition seems relatively secure. After all, the state has legitimately enacted a number of anticipatory or inchoate offenses. These offenses prohibit conduct not because of the harms they cause, but because of the harms they unjustifiably risk. If drug use unjustifiably risks violent crime, its proscription might be warranted by a similar rationale. ${ }^{33}$ Thus the present inquiry about the drug-crime nexus as a public health issue is directly relevant to the issue of criminalization---an investigation into what might justify our current practice of punishing drug users. A strong causal link between drugs and crime might make punishment of use compatible with a public health approach after all.

Regardless of how to understand the precise mechanism that explains the link, the hypothesis that drugs are strongly implicated in violent crime seems plausible. This hypothesis is reinforced by data familiar to policy analysts. Studies consistently show both that drug users are much more involved in criminality than non-users, and that criminals are much more likely to use drugs than non-criminals. ${ }^{34}$ When the quantity of drugs

30 Arguably, philosophers could make a genuine contribution to this issue by clarifying the concept of causation. Commentary on the drug-crime connection relies overwhelmingly on a simplistic counterfactual analysis according to which drug use is thought to cause crime if the latter would not have occurred but for the former. These analyses have been subjected to attacks. See Moore, Causation and Responsibility: An Essay in Law, Morals, and Metaphysics (Oxford University Press 2009) especially Chapter 4.

31 In fact, the topic gets surprisingly little attention. The most eloquent political philosophers of our generation who have earned a reputation for opposing injustice have been silent about whether drug criminalization is justified. I have in mind John Rawls, Ronald Dworkin, Joseph Raz, and Amartya Sen---to name a few.

32 See Husak 2002.

33 See Husak 2008 pp. 159-177.

34 The contested issue is why, not whether these correlations exist. 
consumed by heavy users is at its peak, rates of criminality among these users are greater as well. Moreover, estimates of the amount of property crime perpetrated by drug users range as high as $80 \%$. In addition, interviews and blood tests of inmates typically reveal that more than half used an illicit drug in the month prior to the offense for which they are incarcerated, and nearly a third were under the influence of drugs at the time of their offense. ${ }^{35}$ Finally, broad statistical trends help to confirm the connection between drugs and crime. Rates of violent crime in the United States began to soar around 1985; this increase coincided with a spike in the sale and consumption of crack cocaine---which the Office of National Drug Control Policy then described as 'the most dangerous and quickly addictive drug known to man. ${ }^{36}$

Nonetheless, researchers have expressed doubts about the supposed drug-crime connection. One problem is the difficulty of specifying the mechanism that allegedly links drugs with violence. In particular, psychopharmacological explanations have proved stubbornly resistant to confirmation. Do drugs lead users to act violently because they compromise rationality or because they impair volition? Both possibilities have been contested. Significantly, the effects of drugs in triggering violent behavior differ enormously from one individual to another in the same culture. In addition, the contribution of drugs to violence varies radically across cultures and appears to be learned, ${ }^{37}$ and which is most strongly confirmed in the case of alcohol. But here, as elsewhere, it is difficult to disentangle whether the behavioral effects of substances are a result of their intrinsic chemical properties or of other factors---most notably a result of cultural attitudes and legal regulations. This difficulty is compounded by the fact that drugs are bought and sold in illegal markets, where both buyers and sellers may be ignorant of the purity or quality of the substances they exchange.

How might we test the hypothesis that illicit drugs pose a public health problem because of their causal contribution to violent crime? No experiment that could actually be performed would be ethical. Still, some data that can be gathered in the real world would be suggestive. We might examine correlations between crime rates and drug use at different times in the same place, or in different places at the same time. In what follows, I discuss the former kind of test. If the hypothesis under investigation was true, we would expect (ceteris paribus) that an increase in the use of drugs in a given place would eventually lead to an increase in rates of violent crime, and that a decrease in the use of drugs in a given place would eventually lead to a decrease in rates of violent crime. If rates of violent crime dropped dramatically while drug use remained relatively constant, skepti-

35 See Faupel, Horowitz and Weaver 2010 p. 350.

$36 \quad$ Office of National Drug Control Policy 1989 p. 3.

37 See Fillmore and Vogel-Sprott, Learning, Expectancy, and Behavioral Control Implications for Drug Abuse in Associative Learning and Conditioning Theory, eds. Reilly and Schachtman (Oxford University Press 2011) p. 213. 
cism about the drug-crime connection would be warranted. As I will indicate, this latter combination of facts is exactly what has occurred in New York City in the past twenty years. Crime rates have plummeted throughout the largest city in the United States at the same time as the incidence of illicit drug use remained stable. In describing the data, I will draw heavily from a recent study by Frank Zimring that explores the spectacular crime drop in New York City during the past two decades and the role that drugs played (or did not play) in causing it. ${ }^{38}$

New York City provides a fascinating laboratory in which to examine the relation between drugs and crime. Although the occurrence of violent crime has dropped in nearly every city in the United States in the past generation, its decrease in New York has been especially precipitous. Even though crime rates have flattened or even inched up elsewhere across the United States in the past few years, they continue to fall in our largest city. ${ }^{39}$ Zimring himself characterizes the New York crime drop as 'astounding. ${ }^{40}$ As he summarizes his findings: the magnitude of crime declines from peak rates ranges from $63 \%$ to $94 \%$ with four of the seven 'index' felonies showing a rate drop greater than $80 \%$, and five of the seven over $75 \%$. The most modest declines---theft and aggravated assault--drop by about two-thirds, while the rates of the other crimes decline to less than $20 \%$ of the city's highest recent rates.

More detailed information, of course, is presented in his book. To be sure, doubts have been raised about the accuracy of this remarkable data. ${ }^{41}$ Nonetheless, statistics from independent sources confirm the magnitude of the crime drop. In short, something exceptional is happening in New York that should repay close attention. ${ }^{42}$

It is worth noting that no respectable criminologist predicted that crime rates would fall to anywhere near their present levels. Theories about the causes of violence favored by social scientists from all points along the ideological spectrum suggested that crime could not possibly drop to its current lows. Some criminologists hold that demographics are the best predictors of crime rates. But the numbers of residents of New York aged 15 to 19 ---

38 Zimring, The City That Became Safe: New York's Lessons for Urban Crime and Its Control (Oxford University Press 2011).

39 Crime appears to have increased slightly in several of New York City's precincts since Zimring's data were collected, but the uptick seems inconsequential unless it represents a trend. See Baker: 'Where Crime Is Up Across the Board, More Police but Not Many Jitters', The New York Times (23 August 2011) p. A17.

$40 \quad$ Zimring 2011 p. 4.

41 Commentators sometimes complain that the numbers are inflated. But many of their allegations stem from frustrated New Yorkers who are disappointed by the fact that the police fail to record their reports of relatively minor crimes such as groping. See Baker and Goldstein: 'Police Tactic: Keeping Crime Reports Off the Books', New York Times (30 December 2011).

42 Something less exceptional is happening elsewhere in the nation. Throughout the entire country, crime has dropped while drug use has not. But the data indicate a more consistent and precipitous decline in New York City. See Zimring 2011 pp. 15-17 and pp. 35-43. 
the period of peak criminality---have risen by about 80,000 since 1990 , from 470,000 to 551,000 . Nearly all of this increase took place in the racial and ethnic groups most prone to criminal activity. ${ }^{43}$ Other criminologists embrace economic theories of crime. Yet fluctuations in poverty rates do not explain the data, and we have recently emerged from the greatest economic downturn since the Great Depression of the $1930 \mathrm{~s} .{ }^{44}$ Most importantly for present purposes, many criminologists believe that drug consumption plays a crucial role in crime trends. Since few experts were willing to predict that the incidence of drug use would fall much below its nadir in 1992, rates of crime were expected to remain constant at best. The collective failure of these demographic, economic, and substance abuse explanations of violent crime has inflicted a black eye on the profession of criminology. Zimring himself wonders why 'there have been few attempts in either academic or policy discourse to conduct an extensive autopsy' of the dire predictions of the early 1990s. ${ }^{45} \mathrm{He}$ speculates that 'the public and the political actors involved with policy are much more concerned with what has caused a crime decline than with any negative lessons. ${ }^{36}$ Although I am sure he is correct, it is crucial to appreciate that simplistic views about the drug-crime connection are undermined by empirical findings from New York City. These results are significant not only for understanding the nature of a public health approach to drug policy, but also for assessing the normative issue of drug criminalization itself.

The New York City crime drop is a monumental achievement that merits more publicity and for which many persons deserve praise. Criminologists continue to be divided about the causes of this decline, and I have no original thoughts to contribute about this important topic. ${ }^{47}$ For present purposes, the most remarkable feature of this crime drop is that it has not been accompanied by a significant decrease in the incidence of illicit drug use. Reliable data on drug consumption is notoriously hard to obtain, but one preliminary point should generate agreement: The relevant datum to test a possible drug-crime connection is not the prevalence of illicit drug use per se. Overall figures on illicit drug trends are swamped by fluctuations in the consumption of marijuana, easily the most popular and widely available illicit substance. But no reasonable person believes

43 Although the non-Hispanic Black population declined by $4.8 \%$, the Hispanic youth cohort aged 15-19 grew by 38\%. Id., p. 84.

$44 \quad 19.3 \%$ of New York City residents were below the poverty line in 1990; $21 \%$ were below in 2000, and $21.2 \%$ in 2010. See Roberts: 'As Effects of Recession Linger, Growth in City's Poverty Rate Outpaces the Nation's', New York Times (22 September 2011) A23.

$45 \quad$ Zimring 2011 p. 88.

$46 \quad I d$.

47 Everyone loves to speculate about this matter. See the various opinions expressed in Blumstein and Wallman (eds.), The Crime Drop in America (Cambridge University Press 2000). 
that marijuana is directly implicated in violent crime. ${ }^{48}$ At best, its impact is indirect, that is, as a gateway to the use of other illicit drugs that are implicated in violent crime. Unquestionably the data involving the so-called 'hard drugs'---cocaine (in whatever form) and the opiates (especially heroin)---are more relevant for criminological purposes. New York City has long earned a reputation for housing cocaine and heroin users in far greater numbers than national averages. This fact was frequently cited to explain the high rates of violent crime throughout New York City in the 1980s, especially during the so-called crack epidemic. But how common are cocaine and heroin in New York City today? By all indications, cocaine use has been relatively flat while heroin use may recently have increased---although not nearly as rapidly as in most other cities in the United States. Zimring describes New York as 'a city where drug violence drops by more than $90 \%$ while drug use is relatively stable. ${ }^{49}$

Of course, matters are not so simple. Despite its record-setting proportions, crime might have declined even further had illicit drug use been curbed. Or some other variable(s) might explain why rates of violent crime have dropped dramatically even though the incidence of illicit drug use has remained constant. If some other factor accounts for the data, however, we would need a competing explanation for the surprising results. Among the many possible explanations, two must be rejected at the outset. First, New York has not managed to solve its crime problem by incarcerating large numbers of persons---drug users or otherwise---who would be likely to perpetrate future offenses. Even though the incarceration rate has increased nationally since 1990, New York stands as a striking exception to this generalization. Not only is its overall prison population lower than in 1990, but New York City is locking up a smaller fraction of its population today than in the early and mid-1990s. ${ }^{50}$ Second, one pillar of what I have called the liberal position on drug policy should not be given much credence in explaining the statistics. No evidence indicates that significantly greater numbers of persons have received treatment, or that those who have received treatment have succeeded in remaining abstinent, than in earlier times. Residents are managing to commit fewer crimes than in previous decades, but drug treatment providers should not take much credit for this achievement.

Basic psychopharmacology has not changed. So what has changed in the nexus between drugs and violence during the spectacular crime drop of the past twenty years? No one factor can tell the whole story. But a major difference in this period is the manner in which drugs are bought and sold. Markets---in the sense of a public place where persons

48 In the context of drugs, standards of what passes as reasonable vary radically over time. Harry Anslinger, U.S. Representative to the United Nations Narcotics Commission, remarked in 1962 that 'marijuana is the most violence-causing drug in the history of mankind'. Quoted in Plant et al., Drug Nation: Patterns, Problems, Panics, and Policies (Oxford University Press 2011) p. 129.

$49 \quad$ Id., p. 92.

$50 \quad$ Id., p. 88. 
go to buy a commodity---have been disrupted by intense police activity. ${ }^{51}$ Unlike the era in which markets would simply shift from one block or neighborhood to another, fewer drugs are exchanged in locations known to buyers and sellers---and, therefore, in locations known to the police. Technology has altered drug markets radically. Mobile phones are the most prevalent, but is not the only recent innovation playing a part in drug transactions. A cover story of The Village Voice in 2011, for example, described the active buying and selling of heroin on the Internet by using the craigslist website. ${ }^{52}$ In any event, the noticeable erosion of open drug markets should not be confused with a decrease in drug consumption overall. Zimring observes 'the New York experience may be an outstanding example of successful influence by the police on patters of drug trade without any much greater suppression of the drug traffic and use. ${ }^{53}$ Although many details remain unclear, it seems that the nature of illicit drug markets, and not use itself, plays a more central role in explaining the drug-crime connection. Zimring concludes 'the city may be winning its war on crime (and on drug violence) without winning the war on drug abuse.54

Again, caution must be urged. But if the issue with which we are concerned involves possible rationales for criminalization, it is important to be reminded that the burden of proof in making a case for punishment rests on the state. ${ }^{55}$ Maybe the above results cannot be generalized beyond the particular case of New York City; no two cities are identical in all relevant respects. But the above findings cast so much doubt on the inevitability of a drug-crime nexus that we no longer should be confident that penal laws against drug use are needed for the purpose of preventing violent crime and preserving public health.

\section{How Should the State and Social Institutions Respond to Illicit Drug Users?}

Suppose I am correct that illicit drug use need not create a serious public health problem because of its causal connection to violence generally or to violent crime in particular. Suppose further that this finding undermines the most credible argument for criminalizing the use of illicit drugs. Still, this conclusion remains wholly negative; it does not tell us what the state should do to illicit drug users. My own preference is simple---again, deceptively so. What the state should do to drug users depends on the type of state action involved. I believe that the criminal justice system should leave such persons alone. Again,

51 In particular, Operation Pressure Point in Manhattan utilized 1,000 police officers for six months and made 17,000 felony arrests.

52 See Coscarelli and Shapiro: 'Heroin.com: Selling Junk Online', The Village Voice (20 April 2011).

$53 \quad$ Zimring 2011 p. 99.

$54 \quad$ Id., p. 99.

55 See Husak 2008. 
the claim that the criminal justice system should leave illicit drug users alone is easily misunderstood and becomes more plausible when clarified.

Decriminalizing use per se does not preclude enacting specific laws that target times and places at which drug use creates elevated levels of risk to public health. Thus we mostly leave drinkers of alcohol alone, even though time and place restrictions are common and narrowly-tailored offenses (such as drunk driving) are enforced. But further options are also available; the state may adopt any number of devices to discourage drug use, as long as these devices are not accompanied by punishments. ${ }^{56}$ For example, no one should object to state efforts to promote healthy lifestyles and to educate persons about the hazards of illicit drugs. Even more importantly, institutions other than the state can and do play a significant role in discouraging drug use. After decriminalization, some of these institutions might exert even more influence. Private businesses, schools, insurance companies and universities, to cite just a few examples, might adopt policies that discriminate against drug users. Suppose that employers fired workers and schools penalized students who consumed given drugs. I do not endorse all of these ideas; many seem unwise and destined to backfire. Removing drug users from schools or the workplace, for example, seems destined to increase their consumption. I simply point out that these practices are compatible with decriminalization as I construe it and can be accepted by those who believe the criminal justice system should leave drug users alone.

The claim that the criminal justice system should leave drug users alone should not be understood to imply that these persons do not pose a significant social problem. Instead, the contention is that any coercive device the state might implement to combat these problems is likely to be ineffective, counterproductive, and/or unjust. This contention is not a priori or based on a libertarian ideology about the proper role of government. ${ }^{57}$ Any concrete proposal to employ a coercive state policy against drug use per se must be described in detail and evaluated on its own merits. For the following reason, I am skeptical that any such idea will be persuasive. Approximately 125 million living residents in the United States have consumed an illicit drug at some time in their lives. In light of the fact that their use has caused no significant social problems in the vast majority of cases, any given proposal aimed at this behavior is bound to be overinclusive and to coerce particular individuals without justification. Consequentialists may be prepared to make these trade-offs, but any theorist who thinks our policy toward drug users should be governed by deontological constraints is likely to resist them.

Surely the most trenchant objection to my proposal is that coercive state efforts need to be retained in order to keep the incidence of drug use within acceptable limits. With-

56 See the strategies discussed in Bogart, Permit But Discourage: Regulating Excessive Consumption (Oxford University Press 2011).

57 The libertarian view(s) is/are presented in Boaz (ed.), The Crisis in Drug Prohibition (Cato Institute 1990). 
out punitive state action, won't rates of illicit drug use increase exponentially, with corresponding repercussions for public health? Some commentators deploy sophisticated models and hazard fairly specific predictions about how various policy changes would affect rates of consumption..$^{58}$ To my mind, however, none of these predictions should be taken very seriously. Since I have explained my reservations about the accuracy of these forecasts elsewhere, I will not recount the basis of my skepticism here. ${ }^{59}$

In any event, misgivings about the empirical basis for predictions do not get to the heart of the matter. As I have emphasized, normative issues about punishment for the use of illicit drugs should be governed by deontological constraints, not by the utilitarian calculus of harm-reduction. A criminal law is not justified simply because its absence would produce more disutility overall. ${ }^{60}$ Even on utilitarian grounds, the specter of greater use is not a trump card that may be played against any proposed policy reform. As harm-reduction theorists remind us, more drug use and more drug users need not translate into more drug-related harm. After all, no one should believe that drug consumption is intrinsically bad; it is bad, if at all, only because of its instrumental contribution to other evils. If illicit drug use plays less of an instrumental role in causing other evils than conventional wisdom supposes, we should question why the prospect of greater amounts of such use is viewed as an unmitigated disaster which no sensible commentator should tolerate. Again, there are many possible harms greater drug use might cause; each allegation must be studied separately and carefully. Drug policy presents a huge puzzle that, like most puzzles, is best approached one piece at a time. But if Zimring is correct about the recent experience of New York City, one of the most serious evils to which drug use has been thought to lead---violence generally and violent crime in particular----does not justify punitive policies against illicit drug users.

\section{The Current Opiate Overdose Epidemic}

In my country, and probably most everywhere else, the details of drug policy often lurch from crisis to crisis. The most recent such crisis is the opiate epidemic. The number of deaths attributed to opiate overdose has skyrocketed in recent times, increasing more than four-fold in the past twenty years. Approximately 91 Americans die from an opiate

58 See Kilmer et al.: 'Altered States: Assessing How Marijuana Legalization in California Could Influence Marijuana Consumption and Public Budgets', RAND Report Occasional Paper, http://www.rand.org/pubs/occasional_papers/OP315.html (2010). See also Donohue III, Ewing and Peloquin: 'Rethinking America’s Illegal Drug Policy', Working Paper 16776, National Bureau of Economic Research (February 2011), http://www.nber.org/tmp/88483-w16776.pdf.

59 See Husak, Predicting the Future: A Bad Reason to Criminalize Drug Use, Utah Law Review 105 (2009).

$60 \quad$ See Husak 2008 
overdose every day, a number that exceeds the number of those killed by car accidents and by gun violence combined. Even worse, the epidemic shows no clear signs of abating. This latest crisis represents a national tragedy in health care with which the United States has rarely needed to cope.

I have a reason for saying that 60,000 deaths are attributed to opiate overdose rather than directly caused by it. I urge caution not because I am especially skeptical of statistics that list opiates as implicated in a death. But the vast majority of these fatalities involve polydrug use, and the role of opiates as contrasted with the role of other substances, both licit and illicit, can be hard to disentangle. Moreover, a good many of these deaths involve contaminants or at least substances the user did not realize he was ingesting. Fentanyl, a powerful drug frequently used to tranquilize animals, is increasingly found in substances sold as heroin.

Sociologists should profess a limited understanding of drug trends. They seem to have a life of their own. Like the ups and downs of the stock market, no one has succeeded in predicting when they will start or when they are likely to end. Among the relative mysteries is the geographical distribution of a given epidemic. Although it is now spreading more evenly throughout the country, the most recent wave of opiate overdose deaths began largely in poor and rural regions populated mostly by whites. Facile explanations do not explain this geographical fact. To be sure, unemployment and deprivation are high in these regions. But the economy of the places in which deaths are concentrated has been stagnant for a very long time before opiate use became so common.

No one story describes what has happened to bring about the problem. Here, however, is what I believe to be the most plausible single explanation. Sensitive to allegations that pain is undertreated by the medical profession, doctors began prescribing record numbers of synthetic opiates (e.g., OxyContin and Vicodin) to patients who were suffering or were likely to suffer. The amount of prescription opiates sold to pharmacies, hospitals, and doctor's offices quadrupled from 1999 to 2010, despite the absence of evidence that Americans were suffering more pain. In 2013, for example, providers wrote nearly a quarter of a billion opioid prescriptions---enough for every American adult to have his or her own bottle of pills. Patients rarely used the quantity of pills that were prescribed, but sold or stockpiled their reserves in medicine cabinets. Anyone interested in experimenting with a new drug had ready access to pills made available on the black market. At first, a great many users experience opiate use as incredibly euphoric. By 2014, nearly two million Americans were abusing prescription opioid pain relievers. Many because addicted, finding it very difficult to stop despite efforts to do so. As doctors were blamed for contributing to the epidemic, the number of prescriptions decreased and black market supplies dried up. As a result, many addicts turned to heroin---or what they believed to be heroin---as a substitute. In inflation-adjusted dollars, street heroin has never been cheaper in the United States. But deaths from (what users believe to be) 
heroin are more frequent than deaths from synthetic opiates. As a result of this dynamic, the number of fatalities attributed to opiates continues to increase even while synthetic opiates are less widely available. ${ }^{61}$

I cannot emphasize too strongly that the above scenario represents only one generalization that admits of countless exceptions. A minority of persons became addicted as a result of the very medications to which they were prescribed. Some (especially younger addicts) began directly with heroin and never touched a synthetic opiate. And so on. To my mind, among the most maddening aspects of drug policy in the United States is the supposition that individual variations are relatively unimportant and that generalizations about addicts and addiction apply uniformly throughout a given population. Commentators need to be more sensitive to the substantial differences among addicts, how they experience addiction, and what might be done to help them to overcome whatever problem they may have. In any event, the current opiate crisis has given rise to countless articles and exposes in the mainstream media. A week does not pass without a great newspaper like the New York Times publishing a story about the epidemic. Unsurprisingly, attention is often directed to accounts of how local officials are struggling to deal with it. Many of their efforts are directed toward preventing addicts from dying. Throughout much of the United States, police and emergency medical technicians now carry naloxone, an antidote that reverses the otherwise lethal effects of an opiate overdose. In addition, government has cracked down on the indiscriminate prescribing of the pain medications that helped to cause the original problem. Moreover, treatment facilities are expanding all over the country. Like much else in the United States today, however, discussions of how to fund treatment facilities are highly politicized. One party is pilloried for devoting inadequate resources to the problem. Budget allocations of a 'mere' 45 billion dollars annually are denounced as grossly insufficient to make a dent in the problem. But few ideas about how to actually reduce the opiate epidemic are floated in the media.

As I have indicated, many liberals favor treatment as the best strategy to reduce the harm caused by addiction. As I have also indicated, however, real data about the success of given forms of treatment are almost never made available---and for good reason. Before money is thrown at a given mode of treatment, hard evidence is needed that the plan is more effective in getting addicts to overcome their problem than only the resolve of addicts to quit without the assistance of anything we would describe as treatment. We should not jump upon the treatment bandwagon before we have reviewed evidence about how the many addicts who have succeeded in quitting have actually managed to do so. Quitting without anything we would categorize as treatment is remarkably common. ${ }^{62}$ Center for Disease Control and Prevention, https://www.cdc.gov/drugoverdose/index.html.

62 See Kelly et al., Prevalence and pathways of recovery from drug and alcohol problems in the United States population: Implications for practice, research, and policy, 181 Drug and Alcohol Dependence 162 (2017). 
The increasing unavailability of black market synthetics cannot be expected to curb the opiate epidemic once addicts have made the transition from pharmaceuticals to street heroin. In fact, the substitution of street drugs for prescription medications probably compounds rather than alleviates the problem. In addition, suppose I am correct that nearly all treatment facilities are less efficacious than advertised. If so, what can be done to reverse the existing crisis? Indeed, few good ideas are on offer. Government advertisements to publicize the horrors of addiction have not shown impressive results. School education programs appear to do as much harm as good. In a free society, we should be modest and realistic about what government officials or health care professionals can do about it. Unfortunately, even efforts motivated by the best of intentions have not produced great track records.

In light of the foregoing, it is disappointing that no prominent politician has openly called for the decriminalization of opiate use. In fact, as I have indicated, the progress we have seen in reforming marijuana law throughout much of the country has virtually no parallel with any other controlled substance. How, one might ask, would decriminalization be a solution? The simple answer is that it is not. It is the default position to which we should gravitate when no reasonable solution exists. More to the point, however, decriminalization would reap some clear benefits. In particular, users and those who care for them would be far less reluctant to seek whatever formal or informal assistance might be helpful. The stigma of criminalization would be eroded. More importantly, legalized drugs would be subject to regulatory control and would not contain the contaminants and adulterants that now cause much of the problem. And most importantly of all, the prime beneficiaries of decriminalization would be the persons who presently suffer the hardships of punitive sanctions for their conduct.

Before we despair and lose hope about what should be done, we should remind ourselves of the history of past drug epidemics in the United States. For example, we should ask whatever happened to crack, once billed as the most devastating drug ever to hit the streets? Again, no single answer can begin to tell the complete story. But one prominent explanation is that many younger potential users were dissuaded from using crack after witnessing the destruction caused to their older relatives who were already hooked. Why would I want to wind up like my older brother, whose lifestyle is not something anyone (including himself) could ever admire or want to emulate? If this story is at all accurate, one would expect that the current heroin epidemic, like past drug epidemics in the United States, would wane on its own. I have no idea whether this forecast expresses pessimism or optimism. But I predict that historians of the future will recount this forecast when the crisis has finally peaked and shown signs of significant decline. 